\title{
Intraocular Pressure and Outflow Facility are Unchanged Following Acute and Chronic Intracameral Chondroitinase ABC and Hyaluronidase in Monkeys
}

\author{
W. C. HUBBARDa, M. JOHNSON ${ }^{b}, H . G^{\circ} \mathrm{NG}^{\mathrm{c}}$, B. T. GABELTª, J. A. PETERSONa, \\ R. SAWHNEYc, T. FREDDO', AND P. L. KAUFMANa* \\ ${ }^{a}$ Department of Ophthalmology \& Visual Sciences, University of Wisconsin, ${ }^{\mathrm{b}}$ Department of Mechanical \\ Engineering, Massachusetts Institute of Technology and ${ }^{\mathrm{C}}$ Departments of Ophthalmology and Pathology, \\ Boston University, U.S.A.
}

(Received Columbia 29 August 1996 and accepted in revised form 5 March 1997)

\begin{abstract}
We determined the effect of chronic and acute loss of glycosaminoglycans from the aqueous outflow pathway on intraocular pressure (IOP) and outflow facility in the subhuman primate eye. For the study of the chronic effects of the GAGases, cynomolgus monkeys received intracameral injections of hyaluronidase (Streptomyces, 5 or 50 units, $n=2)$ or chondroitinase ABC $(0 \cdot 05$ or $0 \cdot 25$ units, $n=2)$ biweekly for 8 months (4 months for each dose). IOP was measured at 3, 7, 10 and 14 days after each injection. Outflow facility (2-level constant pressure) was determined at 2, 4, 6, and 8 months. Monkeys were killed 6 days after the last injection. The changes in the distribution of hyaluronic acid and sulfated proteoglycans in the outflow pathway were examined using substrate-specific histochemical techniques. The acute effects of these enzymes on outflow facilities (30 min or $2 \mathrm{hr}$ after enzyme) were determined in another group of animals $\left(n=4\right.$ for each time enzyme $\left.{ }^{-1}\right)$.

IOP and outflow facility were unchanged compared to controls (heat inactivated enzyme) at any time in the chronically or acutely treated monkeys. Hyaluronic acid staining was absent in the outflow pathways of eyes treated chronically with hyaluronidase compared with control eyes, while collagenassociated sulfated proteoglycans were decreased but not completely removed by the chronic chondroitinase $\mathrm{ABC}$ treatment. Chronic loss of these glycosaminoglycans from the trabecular meshwork does not appear to contribute to the IOP elevation and decrease in outflow facility that accompanies openangle glaucoma. Most importantly, no increase in outflow facility was found with acute hyaluronidase or chondroitinase treatment.

(C) 1997 Academic Press Limited

Key words: aqueous humor outflow; chondroitin sulfate; cynomolgus monkey eye; glycosaminoglycans; hyaluronic acid; intraocular pressure; proteoglycans; trabecular meshwork.
\end{abstract}

\section{Introduction}

Glycosaminoglycans (GAGs) and other extracellular matrix components in the trabecular meshwork have been thought to play a central role in normal outflow function. Bárány first noted the possible importance of GAGs in generating aqueous outflow resistance, finding that testicular hyaluronidase halved the outflow resistance of bovine eyes (Bárány, 1953; Bárány and Scotchbrook, 1954); Pedler reported a similar result (1956). While testicular hyaluronidase has been reported to increase outflow facility in guinea-pigs (Melton and DeVille, 1960), rabbits (Knepper, Farbman and Telser, 1984), dogs (Van Buskirk and Brett, 1978), and monkeys (Peterson and Jocson, 1974), the evidence suggests little effect on human eyes (Pedler, 1956; Grant, 1963).

These observations have led to numerous studies aimed at determining the precise role that GAGs play in generating aqueous outflow resistance, and

\footnotetext{
* Reprint requests: Paul L. Kaufman, Department of Ophthalmology and Visual Sciences, University of Wisconsin Clinical Science Center, 600 Highland Ave, Madison, WI 53792-3220, U.S.A.
}

whether altered GAG metabolism, leading to an accumulation of GAGs in the outflow pathway, plays a role in the pathogenesis of primary open-angle glaucoma (POAG). Interestingly, there have been only two studies that have used highly specific GAGases to determine precisely which GAGs are involved in generating outflow resistance. Knepper (1980) found that chondroitinase $\mathrm{AC}$, chondroitinase $\mathrm{ABC}$ and Streptomyces hyaluronidase increased outflow facility in the enucleated rabbit eye in a dose-dependent manner. In the primate eye, Sawaguchi et al. (1992) reported that chondroitinase $\mathrm{ABC}$ decreased IOP compared with control eyes that had received heatinactivated enzymes.

More recently, several studies have prompted a reassessment of the presumed role of GAGs in the normal and glaucomatous eye. Gong et al. (1992; 1994) documented a progressive decrease in both sulfated and non-sulfated GAGs with increasing age in normal human eyes. Furthermore, Knepper et al. $(1989 ; 1996)$ and Gong and Freddo (1994) have both reported that POAG is associated with a loss of hyaluronic acid from the trabecular meshwork. Richardson and Hutchinson (1983) also reported that 
POAG was associated with a loss of glycosaminoglycans from the trabecular meshwork. Gong, Freddo and Johnson (1992) suggested several mechanisms by which GAG loss might elevate IOP.

On the assumption that GAG loss, rather than an increase in GAGs, might be related to the increased outflow resistance in POAG, we asked whether enzymatically-induced GAG degradation on a chronic basis would lead to abnormal trabecular meshwork function and an eventual increase in outflow resistance; conversely, it was also possible that this enzymatic treatment might lead to a pharmacologic trabeculocanalotomy. We determined the effect of both acute and chronic intracameral injection of GAGdegrading enzymes on IOP and total outflow facility in the living cynomolgus monkey eye, and examined trabecular meshwork morphology after chronic injection of these enzymes.

\section{Materials and Methods}

Animals

Four adult cynomolgus monkeys (Macaca fascicularis; 2 males, 2 females) with virgin eyes were chosen for chronic enzyme injections, facility and IOP experiments, and morphologic study. All these experiments were masked, the researchers having no knowledge as to which were the treated or control eyes.

Additional adult cynomolgi, which had previously undergone anterior chamber perfusion but not within the prior 2 months, were selected for the three unmasked acute facility protocols ( $n=4$ for each). Animals were selected only if slit-lamp examination by experienced observers revealed no ocular disease and anterior chambers free from cells or flare.

\section{Anesthesia}

For all injections (excepting those immediately after facility measurements), IOP and slit-lamp examinations, monkeys were anesthetized with i.m. ketamine (10 $\mathrm{mg} \mathrm{kg}^{-1}$ ), supplemented as needed by $5 \mathrm{mg} \mathrm{kg}^{-1}$ at $\sim 45$-min intervals. Additional anesthesia for transcorneal injections was i.m. acepromazine $1 \mathrm{mg} \mathrm{kg}^{-1}$, and topical proparacaine $\mathrm{HCl} 0.5 \%$. Pentobarbital Na anesthesia $\left(35 \mathrm{~m} \mathrm{~kg}^{-1}\right)$ i.m., was used for anterior chamber perfusion experiments. All experiments adhered to the ARVO Statement on the Use of Animals in Ophthalmic and Vision Research.

\section{Series A (Chronic Injections, 8 months)}

Hyaluronidase (Streptomyces hyalurolyticus, Sigma, St. Louis, MO, U.S.A.) 5 or 50 units $(n=2)$, or Chondroitinase ABC (Proteus vulgaris, Sigma, St. Louis, MO, U.S.A.) $0 \cdot 05$ or 0.25 units $(n=2)$ were injected intracamerally into one eye biweekly for 8 months (4 months for each dose, beginning with the lower dose for both enzymes); the contralateral control eye received heat-inactivated enzyme (boiled 10 minutes). Enzyme and heat-inactivated solutions were freshly prepared in Bárány's mock aqueous humor at $\mathrm{pH} \sim 7 \cdot 2$ (range $7 \cdot 1-7 \cdot 3$ ) (Bárány, 1964) for every injection, and filtered through $0 \cdot 2 \mu \mathrm{m}$ filters. Fluorescein sodium $(\sim 0.005 \%)$ was added to confirm enzyme entry into the anterior chamber. The anesthetized monkey was placed supine in a head holder and the eye stabilized with forceps. Transcorneal injections were done under a Zeiss operating microscope (Carl Zeiss, Inc., Oberkochen, Germany), using a 30-gauge needle connected via polyethylene tubing to a micrometer syringe. The entry was beveled so that after removal of the needle the anterior chamber was never lost. Eyes were injected with $10 \mu \mathrm{l}$ of enzyme or $10 \mu \mathrm{l}$ of heat-inactivated enzyme, under blue lighting for visualization of fluorescein. The needles were left in the eye for several min and then removed under the microscope to ensure that no aqueous was lost or intraocular structures injured. Animals received i.m. dexamethasone $1 \mathrm{mg} \mathrm{kg}^{-1}$ the day of injection and on day 3.

IOP was measured with a minified Goldmann tonometer (Kaufman and Davis, 1980) 3, 7, 10 and 14 days after injections, immediately following biomicroscopy. Total outflow facility was determined for $\sim 45 \mathrm{~min}$ at $2,4,6$, and 8 months, in both eyes simultaneously, by 2-level constant pressure $(\sim 3$ and $12 \mathrm{mmHg}$ above spontaneous IOP) perfusion of the anterior chamber with Bárány's mock aqueous humor at $\mathrm{pH} \sim 7 \cdot 2$ (range $7 \cdot 1-7 \cdot 3$ ), using a one-needle technique and correcting for the internal resistance of the perfusion apparatus (Kaufman and Bárány, 1976). Enzyme injections scheduled for the same day as facility measurements were done at the conclusion of those experiments via the needles already in the eyes. The needles remained in the eyes for $30 \mathrm{~min}$ after injection and were removed carefully to assure minimal loss of anterior chamber contents.

Monkeys were killed 6 days after the last facility measurement and injection, and GAG histochemistry of the outflow pathways was examined.

\section{Series B (Acute Outflow Facilities, 30 min after Injection)}

Following determination of baseline outflow facility for $\sim 45 \mathrm{~min}$, freshly prepared enzyme (hyaluronidase 10 or 50 units; chondroitinase $\mathrm{ABC} 0.05$ or 0.25 units, $n=4$ for each) or heat-inactivated enzyme were injected into opposite eyes of a given monkey via a ' $t$ ' piece in the inflow tubing of the perfusion apparatus. Enzyme/placebo was allowed to wash in for $5 \mathrm{~min}$, and the corneas then exposed to cold air flow for $3 \mathrm{~min}$ to enhance convection mixing of the anterior chamber. [Cold air mixing reduces the time needed for an even distribution of a bolus injection, which we have 
established in our laboratory using fluorescein injection. An even distribution is not achieved instantaneously but by 30 minutes (Series B) it is fairly uniform and by 2 hours (Series C) it is certainly uniform.] Inflow was closed for $30 \mathrm{~min}$, then restarted and facility measurements recorded for $\sim 45 \mathrm{~min}$.

Series C (Acute Outflow Facilities 2 hours after Injection, 2 doses)

Baseline facility was determined, and enzyme or heat-inactivated enzyme injections given as in Series B (0.05 units chondroitinase or 5 units hyaluronidase, $n$ $=4$ for each enzyme). Facility was measured for $\sim$ $45 \mathrm{~min}$, beginning $2 \mathrm{hr}$ after enzyme injections. A second higher dose of enzyme or heat-inactivated enzyme $(0 \cdot 25$ units chondroitinase, 50 units hyaluronidase) was then injected into the corresponding eyes. Facility measurements were again recorded for $\sim 45 \mathrm{~min}$ beginning $2 \mathrm{hr}$ after the injections.

\section{Statistical Analysis}

Series A IOP: (1) Applanation IOP measurements under ketamine anesthesia were analysed using linear regression models with parameters for an intercept and slope over time. Separate models were fit for the data from eyes receiving active enzyme (treated) and heat-inactivated enzyme (control), and for the paired differences. Treatment vs. control differences were examined by testing whether the slope and intercept from the regression of the paired differences were significantly different from 0 , using the t-statistic (regression coefficient estimate/standard error of the coefficient) in a 2-tailed test. We did not adjust for repeated measures or for the fact that two measurements (one for each eye) were obtained from each animal; this less conservative analysis increases the likelihood of calling a difference 'significant' (Menage et al., 1995).

(2) In a separate analysis, we (a) calculated the mean of the applanation IOP measurements for each eye of each animal, and the treated vs. control eye differences, for the $0-2,2-4,4-6,6-8,0-4$ and $0-8$ month intervals, then (b) averaged the means for the two animals receiving each enzyme and for all 4 animals together, and (c) looked subjectively for trends between the means for different periods, and (d) compared the differences against $0 \cdot 0$ by the 2 -tailed paired $t$ test (although with so few animals the latter is only indicative rather than statistically meaningful).

(3) In a third analysis, the single bimonthly manometric measurements immediately preceding the facility determinations, made under pentobarbital anesthesia, were evaluated as in (2).

Outflow facility Treated-to-contralateral control eye ratios were compared against 1.0 by inspection and by the two-tailed paired $t$ test (although $n=2$ again renders the latter problematic).

Series B and C IOP Monometric measurements, under pentobarbital anesthesia, were made immediately preceding the baseline and the $30 \mathrm{~min}$ and $2 \mathrm{hr}$ post-enzyme facility determinations. Comparisons of contralateral baseline differences, ipsilateral postenzyme vs. baseline differences, and contralateral post-enzyme differences corrected and uncorrected for baseline differences, were made by the two-tailed paired $t$ test for differences vs. 0.0.

Outflow facility Comparisons of contralateral baseline ratios, ipsilateral post-enzyme vs. baseline ratios, and contralateral post-enzyme ratios corrected and uncorrected for baseline ratios, were made by the twotailed paired $t$ test for ratios vs. $1 \cdot 0$.

\section{Morphological Examination (Chronic Injection Eyes)}

Fixation Each monkey globe was bisected sagitally. One half of each eye was fixed in $4 \%$ formaldehyde in phosphate buffered saline (PBS) and processed for paraffin embedding and hyaluronic acid staining. The other half was fixed in $2.5 \%$ glutaraldehyde in $25 \mathrm{~mm}$ sodium acetate buffer ( $\mathrm{pH} 5.8$ ) and processed for sulfated proteoglycan staining.

One enucleated bovine eye was procured from a local abattoir (Arena \& Sons, Hopkinton, MA, U.S.A.) and transported to the laboratory on ice. The eye was bisected at the equator. The vitreous body was removed and fixed in 4\% formaldehyde in PBS, processed for paraffin embedding and used as a control to test enzyme activity.

\section{Staining Procedures}

Hyaluronic acid Five $\mu \mathrm{m}$ paraffin sections were deparaffinized, rehydrated, and then incubated for 5 min in $3 \% \mathrm{H}_{2} \mathrm{O}_{2}$ to inactivate endogenous peroxidases. After washing, the sections were incubated for 30 min with $4 \%$ non-fat dry milk powder in PBS and then with a biotinylated-hyaluronan binding protein [5 $\mu \mathrm{g} \mathrm{ml}^{-1}$; preparation and specificity of probe reported previously (Green, Tarone and Underhill, 1988)] overnight at $4^{\circ} \mathrm{C}$. The sections were washed three times with PBS containing $0.05 \%$. Tween 20 and incubated with Streptavidin-biotin-horseradish peroxidase complex (1:500 dilution; Vector Lab, Burlingame, CA, U.S.A.) for $1 \mathrm{hr}$. After three washes in PBS $/ 0.05 \%$ Tween 20, the sections were incubated with $0 \cdot 2 \%$ 3-amino-9-ethylcarbazole (AEC, Sigma Co., St. Louis, MO, U.S.A.) and $3 \% \mathrm{H}_{2} \mathrm{O}_{2}$ in acetate buffer at $\mathrm{pH} 5.2$ for $15-18 \mathrm{~min}$, counter-stained in Mayer's hematoxylin and covered with coverslips. Photographs were taken with a Leitz photomicroscope (Leica Inc., St. Galen, Switzerland). Two quadrants 


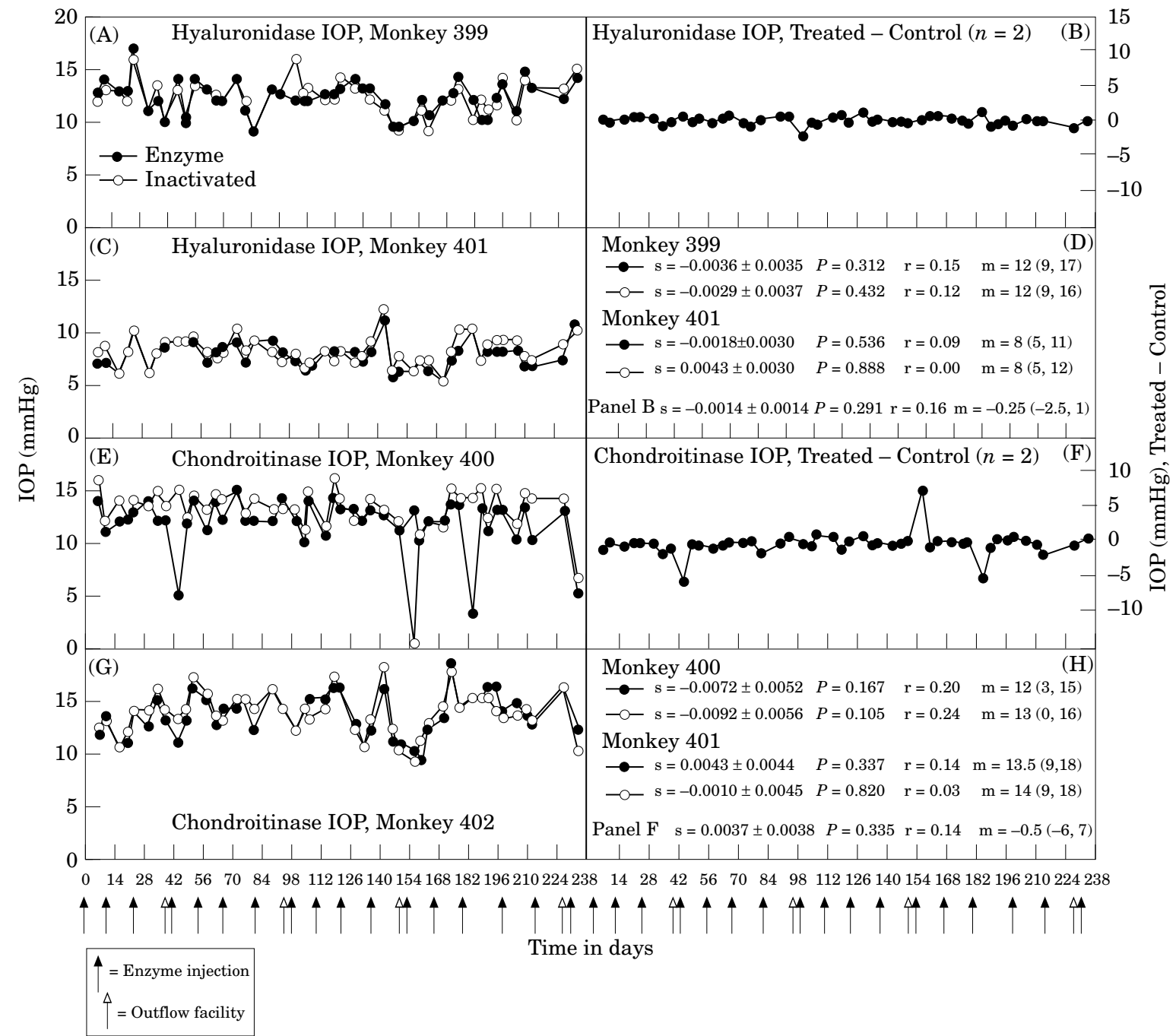

FIG. 1. IOP measurements from monkeys receiving hyaluronidase (A)-(D) of chondroitinase ABC ((E)-(H) every 2 weeks for 8 months. IOP measurements taken with minified Goldmann applanation tonometer under ketamine anesthesia. Solid arrows indicate enzyme injection dates. Open arrows indicate perfusion outflow facility dates. In panels $\mathrm{D}$ and $\mathrm{H}$, m $=$ median (minimum, maximum) IOP values for the entire time course (median, unlike mean, does not reflect outliers); s $=$ slope $\left(\Delta \mathrm{mmHg}\right.$ day $\left.^{-1}\right) \pm$ standard error obtained from least square regression analysis of IOP measurements on time points; $\mathrm{p}$ values indicate probability that slope $=0 \cdot 0 ; r=$ correlation coefficient.

from each eye were examined. Four sections from each quadrant were stained each time. The staining procedure was repeated four times.

The vitreous body in the same sections was used as a positive control. Treating the alternate sections of each specimen with $100 \mathrm{U} \mathrm{ml}^{-1}$ of Streptomyces hyaluronidase (Sigma) for $3 \mathrm{hr}$ at $37^{\circ} \mathrm{C}$ before staining served as an additional control.

Cuprolinic blue After prefixation for $3 \mathrm{hr}$ in $2.5 \%$ glutaraldehyde in $25 \mathrm{~mm} \mathrm{Na}$ acetate buffer, specimens were washed in $25 \mathrm{~mm} \mathrm{Na}$ acetate buffer overnight. The anterior chamber angle tissue, including the trabecular meshwork, the periphery of the cornea, iris and ciliary body of each eye, was then cut radially into small pieces and transferred into a mixture of $0.2 \%$ cuprolinic blue, $0.3 \mathrm{M} \mathrm{MgCl}_{2}$ and $2.5 \%$ glutaraldehyde and stained for $20-24 \mathrm{hr}$ at room temperature. After rinsing with $25 \mathrm{~mm} \mathrm{Na}$ acetate buffer, the specimens were washed in aqueous $0.5 \% \mathrm{Na}$ tungstate and then alcoholic $(50 \% \mathrm{v} / \mathrm{v}) \quad 0.5 \% \mathrm{Na}$ tungstate, dehydrated and embedded in epon-araldite. Semi-thin sections for light microscopy were cut to provide orientation for electron microscopy. Ultrathin sections were cut, counter-stained with uranyl acetate and examined in a Philips-300 electron microscope (Philips, Eindhoven, The Netherlands).

Enzyme activity test The enzyme activities of Streptomyces hyaluronidase and chondroitinase $\mathrm{ABC}$ were tested at the same concentrations as were used in the physiological experiments. Bovine vitreous sections were treated with Streptomyces hyaluronidase (5U $150 \mu \mathrm{l}^{-1}$ and $50 \mathrm{U} 150 \mu \mathrm{l}^{-1}$ ) and chondroitinase $\mathrm{ABC}\left(0 \cdot 05 \mathrm{U}\right.$ and $\left.0 \cdot 25 \mathrm{U} 150 \mu \mathrm{l}^{-1}\right)$ in Bárány's mock aqueous humor, $\mathrm{pH} 7 \cdot 4$, for $1 \mathrm{hr}$ at $35^{\circ} \mathrm{C}$ before hyaluronic acid staining. Chondroitinase ABC's activity to collagen-associated sulfated proteoglycans 


\section{TABLE I}

Total outflow facility after chronic intracameral injection of enzyme or heat-inactivated enzyme

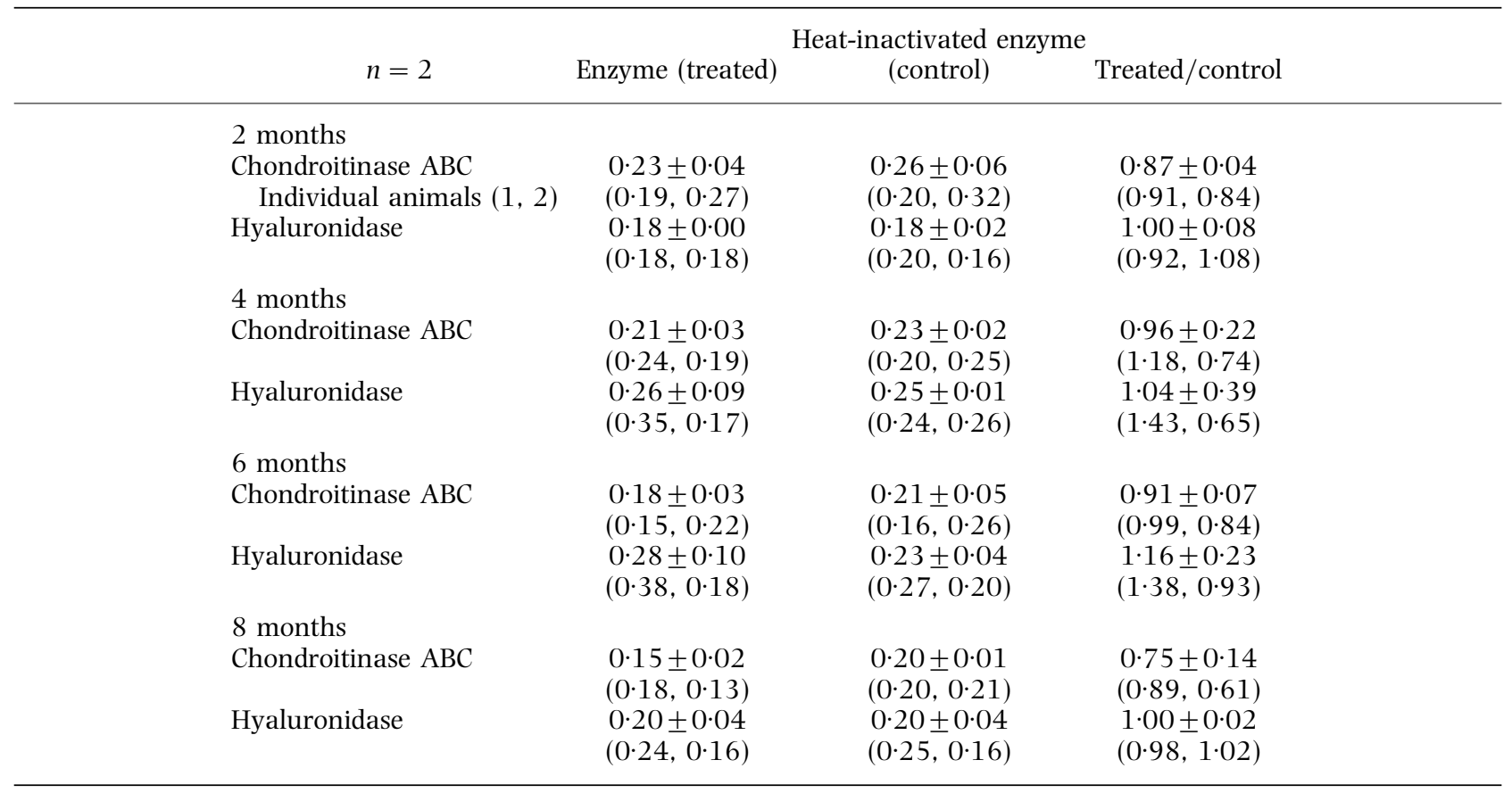

Injections were given biweekly for 8 months to the same eyes. First 4 months doses were $0 \cdot 05$ units chondroitinase and 5 units hyaluronidase. Second 4 months doses were $0 \cdot 25$ units chondroitinase and 50 units hyaluronidase. Facility data are mean + s.E.M. $\mu \mathrm{l} \times \mathrm{min}^{-1} \times \mathrm{mmHg}^{-1}$ for 2 monkeys for each of the two enzymes, each monkey contributing one enzyme and one heat-inactivated enzyme eye; ratios are unitless. Ratios were not significantly different from $1 \cdot 0$ by the two tailed paired $t$ test; all $P \geqslant 0 \cdot 20$.

TABLE II

Reservoir flow after chronic intracameral injection of enzyme or heat-inactivated enzyme

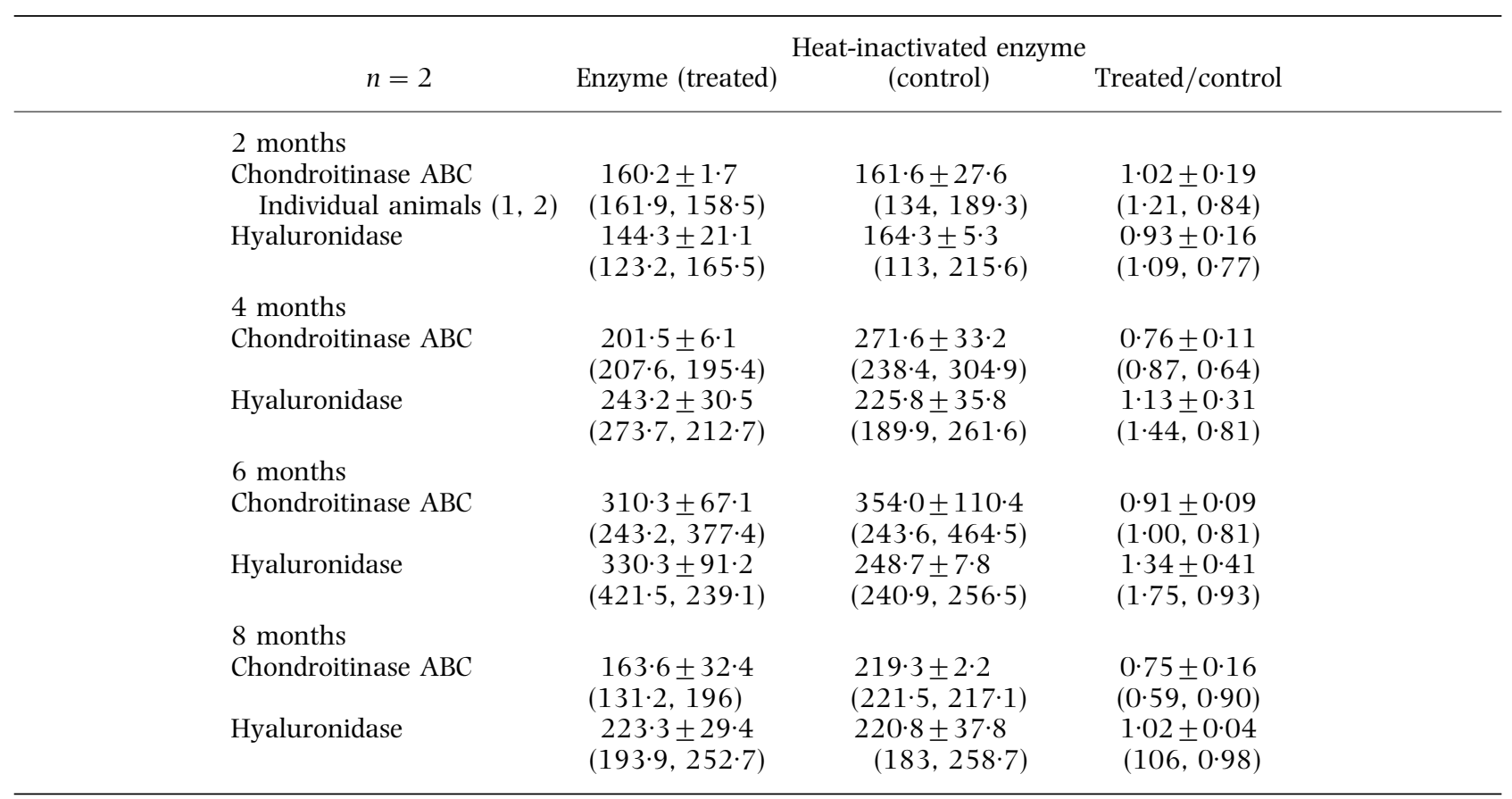

Injections were given biweekly for 8 months to the same eyes. First 4 months doses were $0 \cdot 05$ units chondroitinase and 5 units hyaluronidase. Second 4 months doses were $0 \cdot 25$ units chondroitinase and 50 units hyaluronidase. Flow data are mean \pm S.E.M. $\mu$ l over $\sim$ 45 min for 2 monkeys for each of the two enzymes, each monkey contributing one enzyme and one heat inactivated enzyme eye monitored for exactly the same time; ratios are unitless. Ratios were not significantly different from $1 \cdot 0$ by the two tailed paired $t$ test; all $P \geqslant 0 \cdot 20$. 


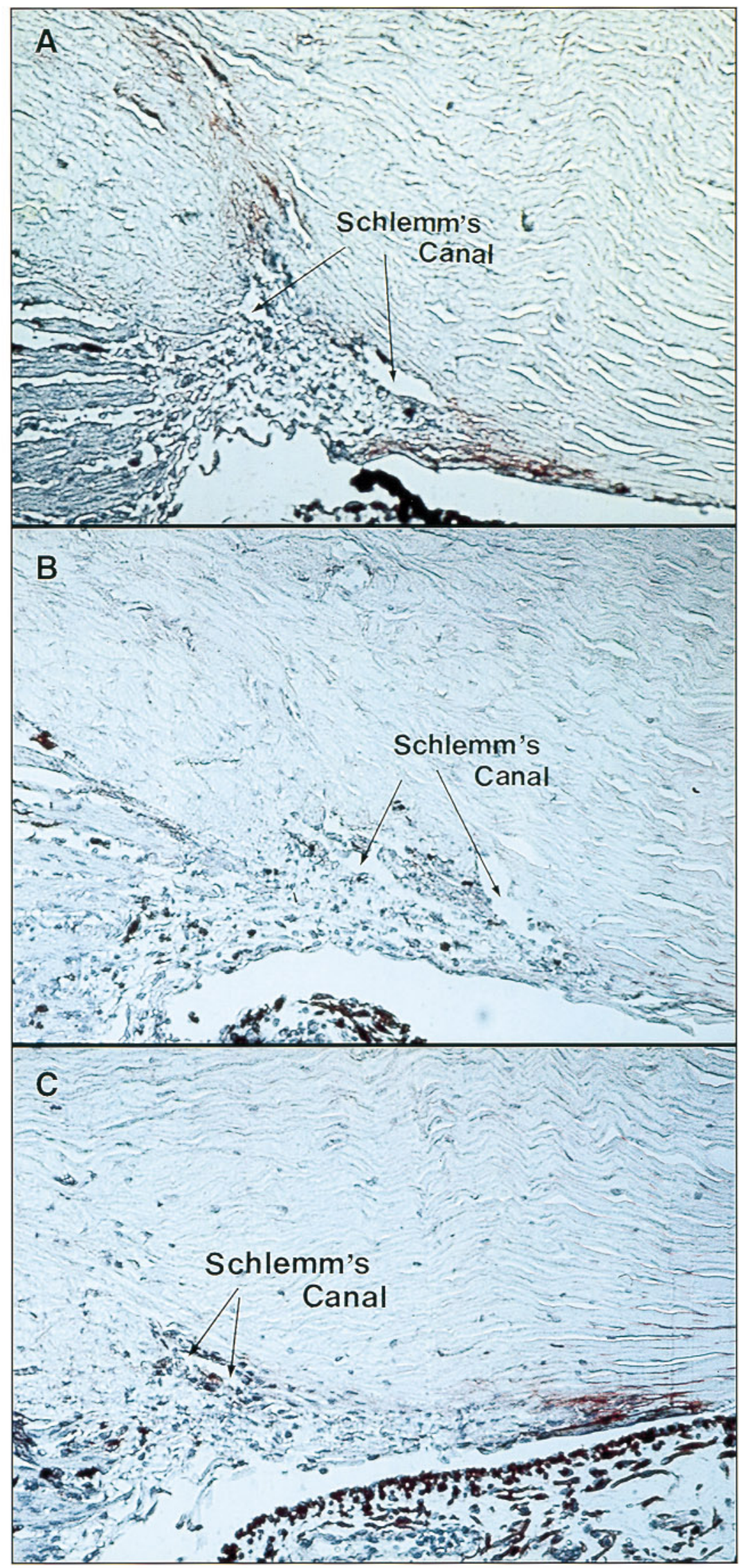

Fig. 2. Distribution of hyaluronic acid. (A) Monkey eye injected with heat-inactivated hyaluronidase ( 5 U for 4 months; 50 U for 4 months; animal killed 6 days after last injection of enzyme). Hyaluronic acid (demonstrated by red staining) was present in the anterior non-filtering part of the trabecular meshwork. Less was evident surrounding Schlemm's canal, collector 
was also tested. Monkey trabecular meshwork tissue sections were treated with chondroitinase $\mathrm{ABC}$ for $1 \mathrm{hr}$ at $35^{\circ} \mathrm{C}$ before cuprolinic blue staining.

\section{Results}

\section{Chronic Experiments (Series A)}

Biomicroscopy at 3, 7 and 10 days after each injection revealed no major differences between enzyme-injected and contralateral control eyes. All eyes tolerated the repeated injections well. The milk transient post-injection/post-perfusion corneal haze and/or punctate epithelial loss and modest anterior chamber cells/flare were no more than expected after such manipulations.

IOP was unchanged in the treated, control, or treated as compared to control eyes, for either enzyme over any time interval in these chronically treated animals, whether the measurements were taken frequently by applanation tonometry under ketamine anesthesia (Fig. 1) or bimonthly by manometry immediately preceding facility measurements under pentobarbital anesthesia (data not shown). Similarly, total outflow facility in enzyme-treated eyes was not consistently altered for either enzyme (Table I).

Unconventional (uveoscleral) outflow is largely pressure-independent (Bill, 1975). Since IOP and facility in our treated and control eyes was the same, and under the reasonable assumption that neither the active nor heat-inactivated enzymes affected aqueous humor formation, any differences between contralateral eyes in fluid flow rate from the external reservoir of the perfusion apparatus into the eye would reflect in large part differences in uveoscleral outflow between the eyes. No such differences in reservoir flow were noted for either enzyme at any of the measurement time points $(2,4,6$ or 8 months; Table II).

No morphologic evidence of a chronic inflammatory cell infiltrate was present in the tissues examined, suggesting that no sensitization occurred following repeated enzyme administration. Histochemical examination showed that in the eyes receiving heatinactivated hyaluronidase biweekly for eight months, hyaluronic acid staining was found in the anterior non-filtering part of the trabecular meshwork, and to a lesser extent surrounding Schlemm's canal, collector channels and blood vessels in the sclera [Fig. 2(A)]. In contrast, in eyes receiving hyaluronidase biweekly for eight months there was no hyaluronic acid staining in the trabecular meshwork or surrounding Schlemm's canal [Fig. 2(B)]. In the eyes receiving chondroitinase $\mathrm{ABC}$ biweekly for eight months, there was no difference in the distribution of hyaluronic acid compared with the heat-inactivated chondroitinase ABC control [Fig. 2(C)].

Pre-treatment of both bovine vitreous body and monkey anterior segment sections with Streptomyces hyaluronidase completely eliminated the hyaluronic acid staining, indicating that the enzyme preparation was active. We also examined the activity of the chondroitinase $\mathrm{ABC}$ on bovine vitreous hyaluronic acid using $0 \cdot 05 \mathrm{U}$ and $0 \cdot 25 \mathrm{U} / 150 \mu \mathrm{l}$. There was no effect on hyaluronic staining at the lower concentration; at the higher concentration, the intensity of hyaluronic staining was reduced compared with heatinactivated enzyme controls.

In eyes receiving heat-inactivated chondroitinase ABC biweekly for eight months, cuprolinic blue staining showed that in both the juxtacanalicular connective tissue and trabecular beams, the proteoglycan-cuprolinic blue complexes were found associated with the cell surface, basement membrane, and collagen fibers (Fig. 3). In eyes receiving chondroitinase ABC biweekly for eight months, collagenassociated proteoglycans were reduced but not eliminated (Fig. 4). The basement membrane-associated proteoglycans were unchanged compared to the eyes injected with heat-inactivated enzyme (Figs 3 and 4). The collagen-associated proteoglycan-cuprolinic blue complexes were eliminated when the tissue was treated with chondroitinase $\mathrm{ABC}$ before cuprolinic blue staining (Fig. 5), indicating that the enzyme preparation was active.

\section{Acute Experiments (Series B and C)}

For all doses of both enzymes, there were no significant differences between treated (active enzyme) and contralateral control (inactivated enzyme) eyes in outflow facility $30 \mathrm{~min}$ or $2 \mathrm{hr}$ after injection [Streptomyces hyaluronidase, Fig. 6(A)-(D); chondroitinase ABC, Fig. 7(A)-(D)]. The increased outflow facility seen at $30 \mathrm{~min}$ and $2 \mathrm{hr}$ compared to baseline in both experimental and control eyes is due to perfusioninduced resistance wash-out (Kaufman, True-Gabelt and Erickson-Lamy, 1988). For neither enzyme was there a difference between treated and control eyes with regard to: (1) spontaneous IOP after anterior chamber cannulation but before the external reservoirs were opened (not shown); (2) IOP at the end of the $30 \mathrm{~min}$ or $2 \mathrm{hr}$ post-injection closed-reservoir

channels and blood vessels in the sclera $(\times 110 \cdot 5)$. (B) Opposite eye injected with hyaluronidase every 2 weeks for 8 months ( $5 \mathrm{U}$ for 4 months; $50 \mathrm{U}$ for 4 months; animal killed 6 days after last injection of enzyme). Hyaluronic acid staining in the anterior non-filtering part of the trabecular meshwork and surrounding Schlemm's canal was essentially absent $(\times 110 \cdot 5)$. (C) Monkey eye injected with chondroitinase ABC every 2 weeks for 8 months ( $0 \cdot 05 \mathrm{U}$ for 4 months; 0.25 U for 4 months; animal killed 6 days after last injection of enzyme). Hyaluronic acid staining was present in the anterior non-filtering part of trabecular meshwork, and to lesser extent surrounding Schlemm's canal $(\times 110 \cdot 5)$. 

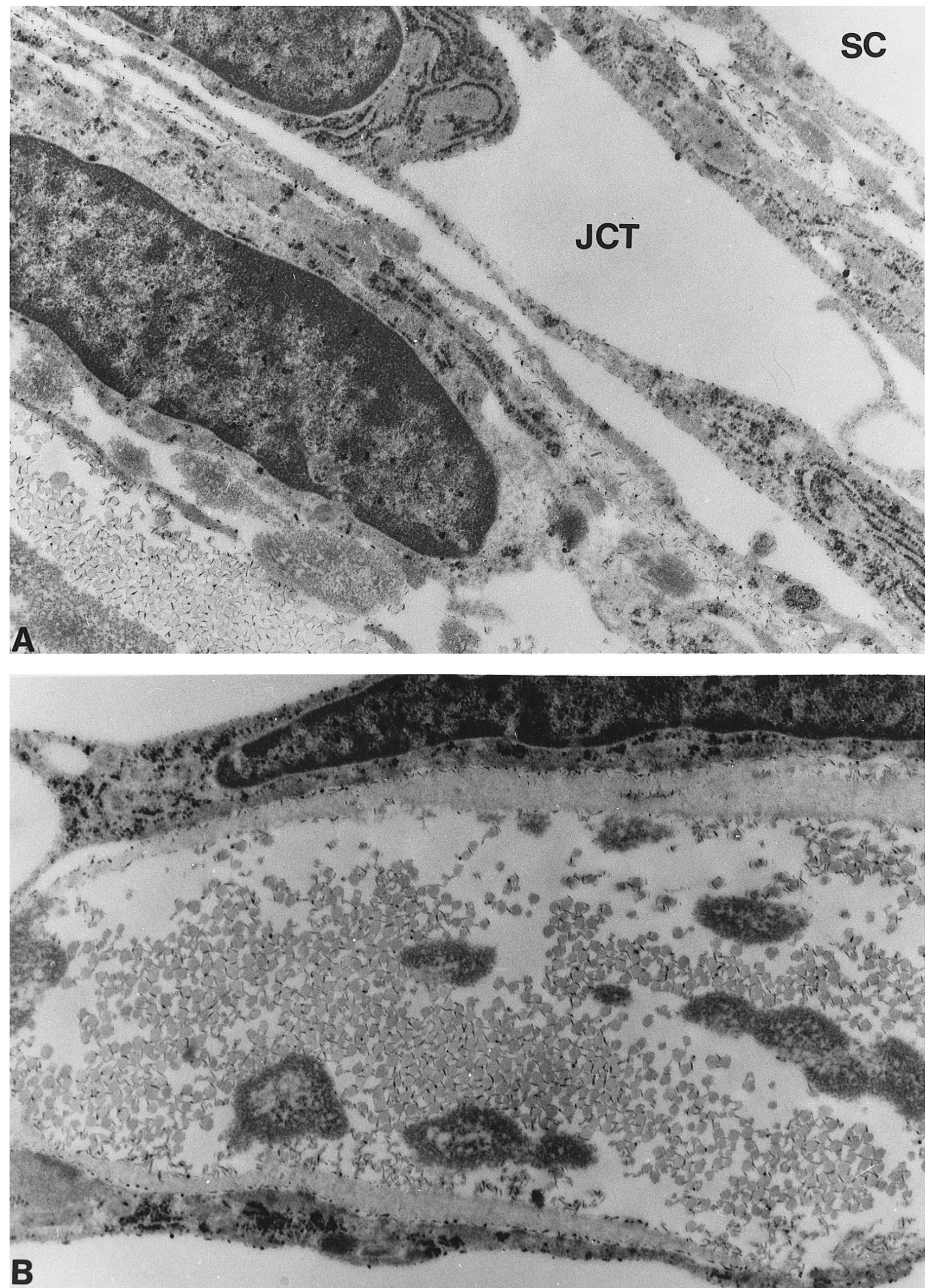

FIG. 3. Distribution of sulfated proteoglycans. Monkey eye injected with heat-inactivated chondroitinase ABC every 2 weeks for 8 months ( $0.05 \mathrm{U}$ for 4 months; $0.25 \mathrm{U}$ for 4 months; animal killed 6 days after last injection of enzyme). In both the JCT area (A) and trabecular beam (B), the proteoglycan-cupronilic blue (PG-CB) complexes (black stick-like figures or black dot) were found associated with the cell surface, basement membrane, and collagen fibers $(\times 29687)$. SC $=$ Schlemm's canal; JCT $=$ Juxtacanalicular connective tissue. 

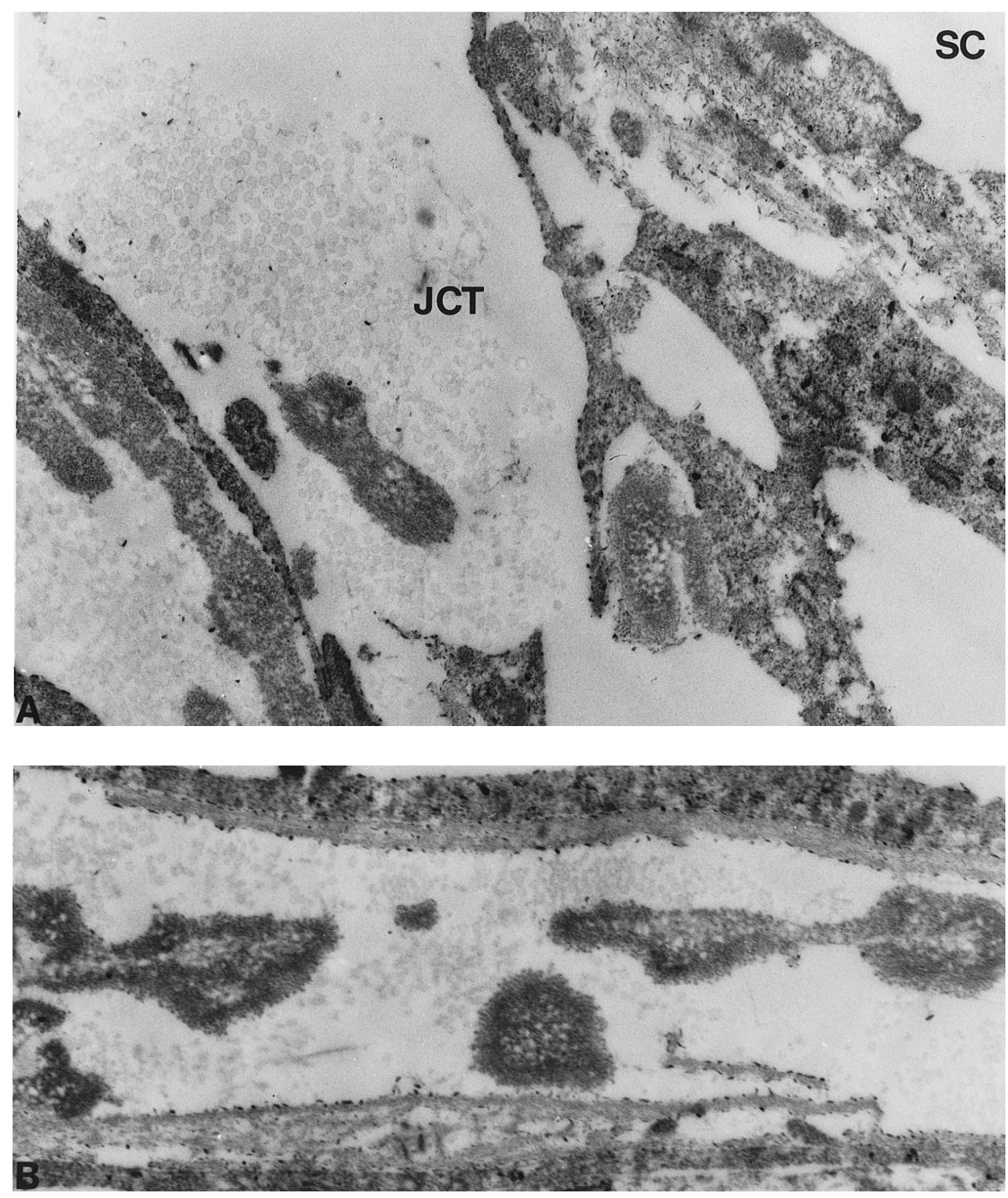

FIG. 4. Distribution of sulfated proteoglycans. Monkey eye receiving chondroitinase ABC every 2 wk for 8 months $(0 \cdot 05 \mathrm{U}$ for 4 months; $0 \cdot 25 \mathrm{U}$ for 4 months; animal killed 6 days after last injection of enzyme). In both the JCT area (A) and the trabecular beams (B), the collagen-associated PG-CB complexes (black stick-like figures or black dot) were reduced but not eliminated compared to the eyes injected with heat-inactivated enzyme (Fig. 3). The PG-CB complexes associated with the basement membrane and cell surfaces were unchanged $(\times 29687)$. SC $=$ Schlemm's canal; JCT $=$ Juxtacanalicular connective tissue.

waiting period (not shown); or (3) fluid flow from the external reservoir into the eye during the facility measurements after the reservoirs were reopened [Streptomyces hyaluronidase, Fig. 6(E)-(H); chondroitinase ABC, Fig. $7(\mathrm{E})-(\mathrm{H})$ ], again suggesting that uveoscleral outflow was unaltered.

\section{Discussion}

Several investigators (Richardson and Hutchinson, 1983; Knepper et al., 1989, 1996; Gong and Freddo, 1994) have shown that POAG is associated with a loss of hyaluronic acid and/or GAGs from the trabecular 

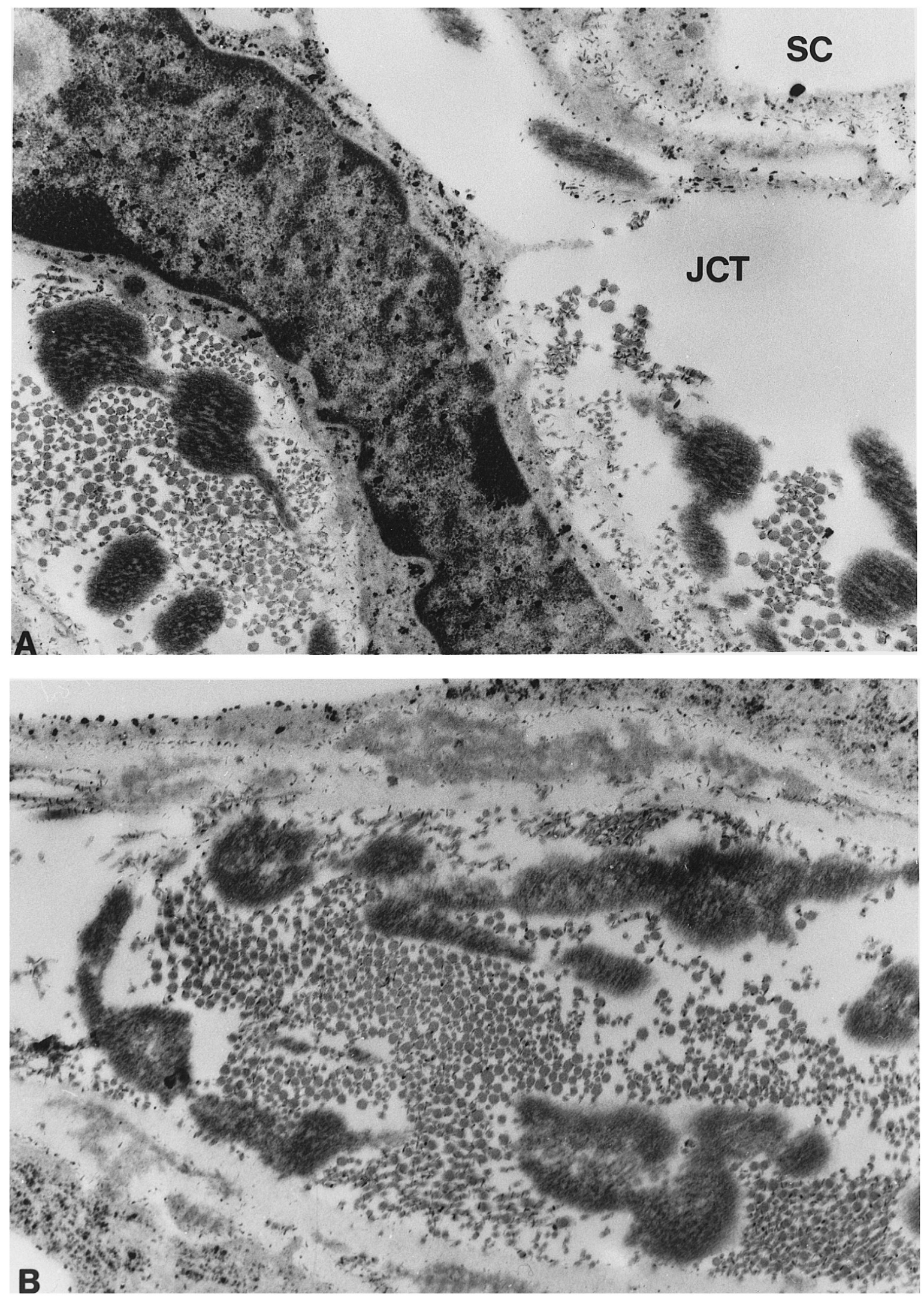

Fig. 5. Chondroitinase $\mathrm{ABC}$ activity. Monkey eye injected with heat-inactivated enzyme every 2 weeks for 8 months $(0 \cdot 05 \mathrm{U}$ for 4 months; $0 \cdot 25 \mathrm{U}$ for 4 months; animal killed 6 days after last injection of enzyme) and treated with chondroitinase $\mathrm{ABC}$ on the sections before cuprolinic blue staining. In both the JCT area (A) and trabecular beam (B), the collagen-associated PG-CB complexes (black stick-like figures or black dot) were eliminated after pre-treatment with chondroitinase ABC, but PGCB complexes associated with the basement membrane and cell surface remained unaffected $(\times 29687)$. SC $=$ Schlemm's canal; JCT $=$ Juxtacanalicular connective tissue. 


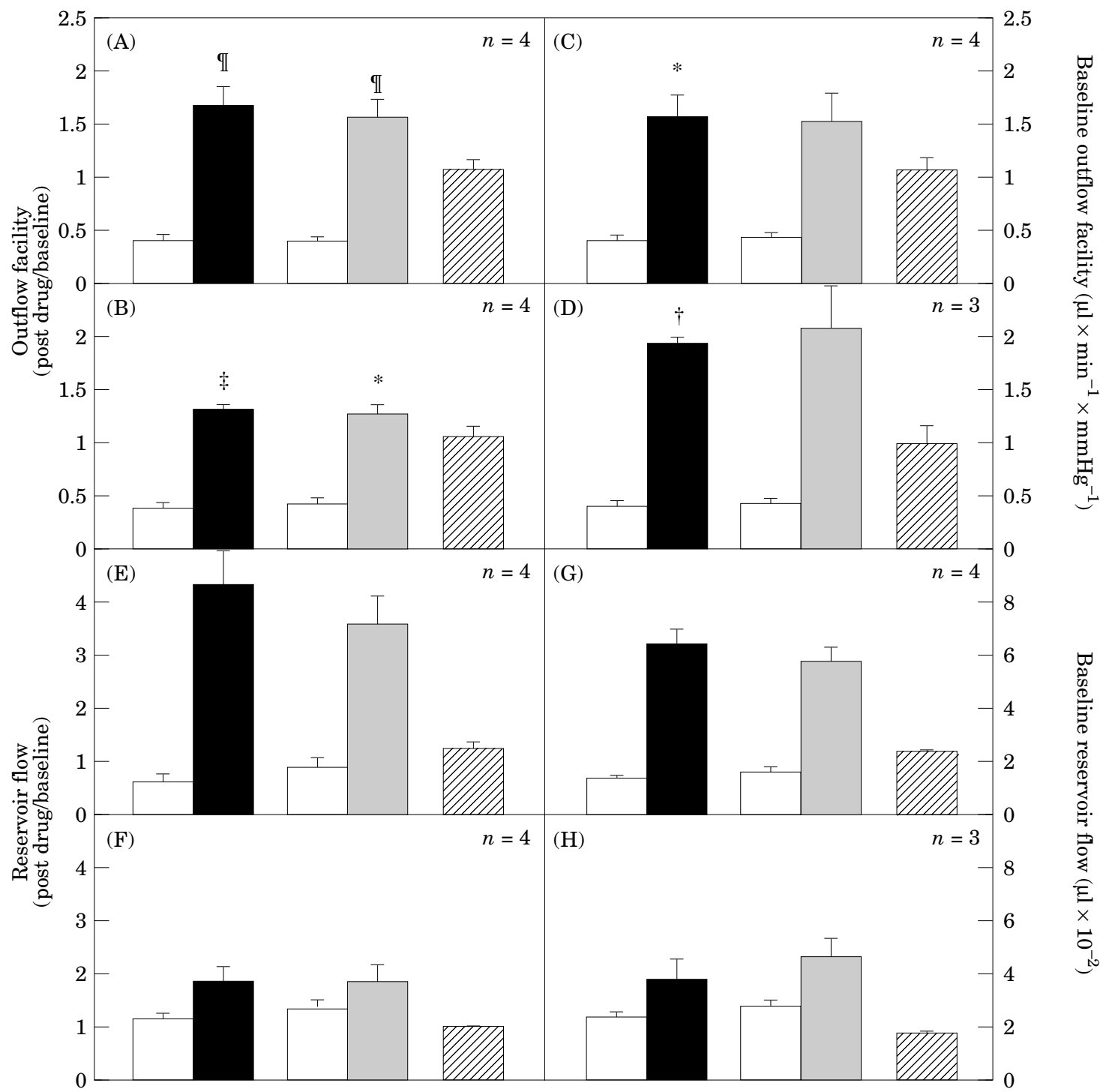

Fig. 6. Acute outflow facility (A)-(D) and reservoir flow (E)-(H) responses to intracameral Streptomyces hyaluronidase in monkeys. Solid, stippled or dashed bars (units on left ordinate) are mean \pm s.E.M. ratio of post drug/baseline facility or flow 30-75 min (A), (C), (E), (G) or 120-165 min (B), (D), (F), (H) after 10 (A), (E), 5 (B), (F) or 50 (C), (D), (G), (H) units of Streptomyces hyaluronidase (Hylase $\square$ ) or heat-inactivated enzyme (IN 國) in contralateral eyes of $n$ monkeys. Clear bars ( $\square$ ) (units on right ordinate) represent baseline facility or flow for corresponding Hylase or IN eyes. Ratio significantly different from $1 \cdot 0$ by the 2 -tailed paired $t$-test: ${ }^{*} P<0 \cdot 1, \dagger P<0 \cdot 01, \uparrow P<0 \cdot 05, \dagger P<0 \cdot 005$. 罝, Hylase/IN.

meshwork. Based on these results, we postulated that chronic enzymatic degradation of the GAGs in the aqueous outflow pathway might lead to an animal model of the disease. However, our results show that chronic loss of GAGs from the aqueous outflow pathway in monkeys neither increases IOP nor decreases outflow facility.

It is possible that more frequent enzyme injections may have been necessary to prevent rapid resynthesis of the GAGs; however, our histochemical results showed that hyaluronic acid was absent from the outflow pathway and sulfated GAGs were reduced in animals killed 6 days after their last injection. It is also possible that the monkey eye is not a good model for glaucoma in the human, or that the absence of staining after enzyme treatment may not reflect the same situation as when GAGs are lost from the outflow pathway in glaucoma. However, our results do not provide support for the hypothesis that POAG results from a loss of GAGs in the outflow pathway.

An unexpected finding in our study was that injection of Streptomyces hyaluronidase or chondroitinase $\mathrm{ABC}$ not only did not have an effect when given chronically, it also did not increase outflow facility acutely. Our hyaluronidase findings contrast with those of Peterson and Jocson (1974) who found a $40 \%$ reduction of outflow resistance in the enucleated rhesus monkey eye $15 \mathrm{~min}$ after intracameral introduction of $100 \mu \mathrm{l}$ of bovine testicular hyaluronidase in saline (150 U). This discrepancy may be due to differences in enzyme specificity since testicular hyaluronidase is known to affect other moieties besides hyaluronic acid (Ohya and Kaneko, 1970; Keiser and Hatcher, 1979). We note here that the highest enzyme 


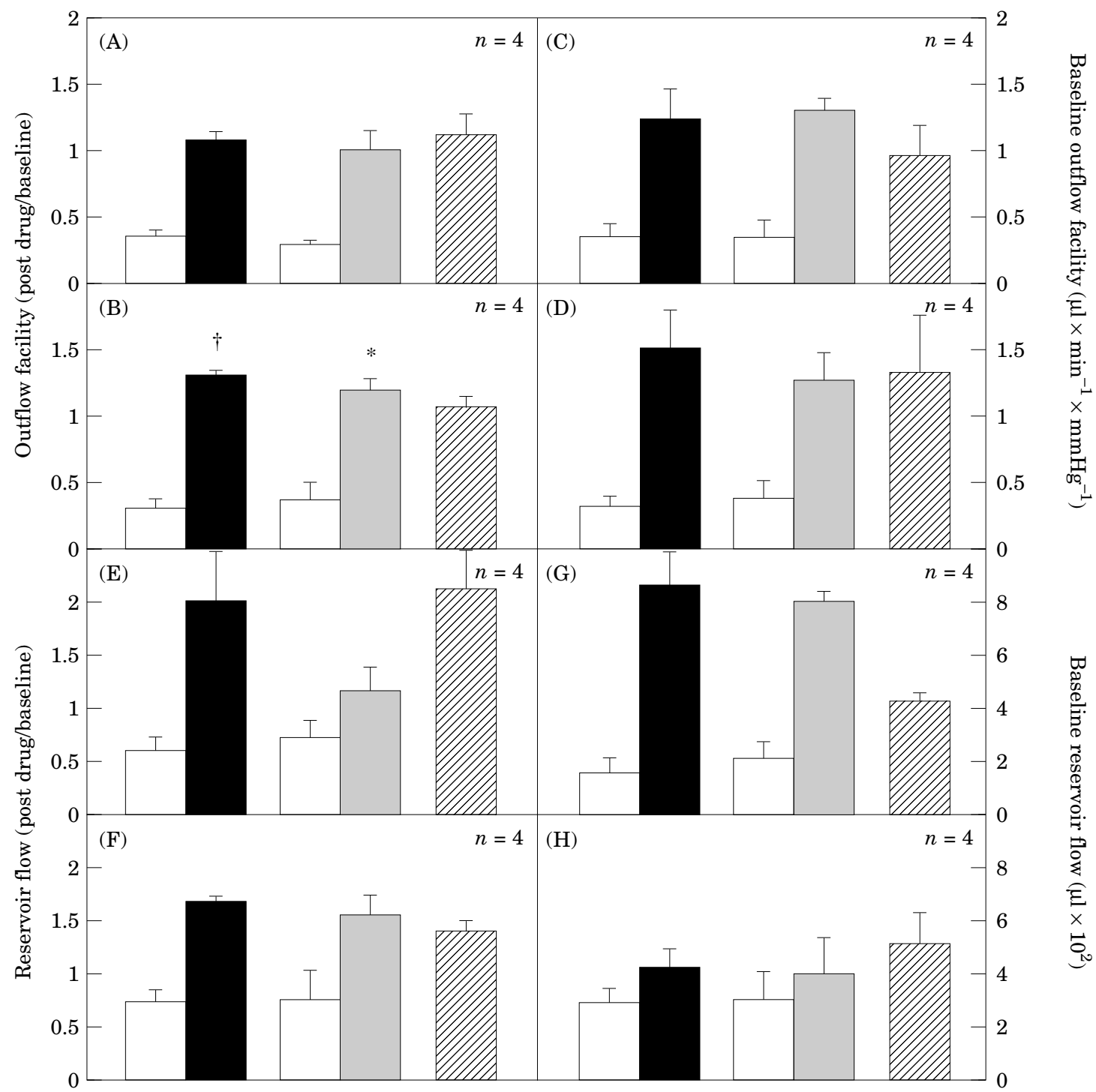

Fig. 7. Acute outflow facility (A)-(D) and reservoir flow (E)-(H) responses to intracameral chondroitinase ABC in monkeys. Solid, Stippled or dashed bars (units on left ordinate) are mean \pm s.E.M. ratio of post drug/baseline facility or flow $30-75$ min (A), (C), (E), (G) or 120-165 min (B), (D), (F), (H) after 10 (A), (E), 5 (B), (F) or 50 (C), (D), (G), (H) units of chondroitinase ABC (Cabc $\square$ ) or heat-inactivated enzyme (IN 眯) in contralateral eyes of $n$ monkeys. Clear bars (units on right ordinate) represent baseline facility or flow for corresponding Cabc or IN eyes. Ratio significantly different from $1 \cdot 0$ by the 2 -tailed paired t-test: ${ }^{*} P<0 \cdot 1, \dagger P<0 \cdot 01, \uparrow P<0 \cdot 05, \dagger P<0 \cdot 005$. 四, Hylase/IN.

dosages we used were 5-fold higher than those used by Knepper et al. (1984) (rabbits: Streptomyces hyaluronidase) or Sawaguchi et al. (1992) (monkeys: chondroitinase $\mathrm{ABC}$ ).

Our chondroitinase results differ from those of Sawaguchi et al. (1992), who found that chondroitinase $\mathrm{ABC}$ (in three cynomolgus monkeys) decreased IOP, using the same enzyme, and methods very similar to our own. These conflicting results could possibly be due to differing techniques of intracameral drug delivery. Sawaguchi et al. first withdrew $150 \mu \mathrm{l}$ of aqueous from the anterior chamber (more than the anterior chamber volume in this species; Erickson et al., 1984) and then slowly introduced $200 \mu \mathrm{l}$ of chondroitinase $\mathrm{ABC}$ solution (0.05 U) (twice the normal anterior chamber volume). These manipulations themselves, leading respectively to anterior chamber collapse and hyperexpansion, could abet disruption of trabecular meshwork architecture. In our experiments we injected essentially atraumatically $10 \mu \mathrm{l}$ of enzyme solution containing either $0.05 \mathrm{U}$ or $0.25 \mathrm{U}$. The difference in results could also involve the small number of animals examined in both studies.

Most of the proteoglycan-cuprolinic blue complexes associated with basement membrane and cell surfaces are heparan sulfate, which can be digested by heparitinase, but not by chondroitinase ABC (Gong et al., 1992; Bernfield et al., 1992). With this possible exclusion, the absence of either an acute or chronic effect on outflow facility in the present studies on live monkeys, despite histochemical evidence of GAG loss in chronically enzyme-treated eyes and demonstration that the enzymes were active, does not support the 
widely held view that hyaluronic acid or the sulfated GAGs play an important role in outflow resistance, at least in the monkey eye. This is surprising in view of the considerable number of studies conducted on the possible role of GAGs in outflow dynamics and POAG (e.g. Knepper et al., 1984; Acott et al., 1985; Johnson, Bradley and Acott, 1990; Gong et al., 1992). Since the cuprolinic blue staining of the core proteins requires sulfated GAG residues to bind (Tawara, Varner and Hollyfield, 1989), and the hyaluronic acid binding protein may require a minimum length of hyaluronic acid to bind, one may speculate that enzyme treatment does not entirely remove the GAGs but only decreases their staining potential. However, our use of relatively high enzyme concentrations should have minimized this possibility.

Prostaglandin $\mathrm{F}_{2 \alpha}$ and various analogs increase uveoscleral outflow (Crawford and Kaufman, 1987; Gabelt and Kaufman, 1989; Nilsson et al., 1989) in human and monkey eyes by acting as a hormonal to signal to remodel the connective tissue between the ciliary muscle bundles (Kashiwagi et al., 1995; Kaufman and Crawford, 1989; Kaufman and Gabelt, 1995; Lindsey et al., 1996; Tamm, Lütjen-Drecoll and Rohen, 1990; Tamm, Rittig and Lütjen-Drecoll, 1990). The studies to date suggest that the turnover of some types of collagen is altered (Tamm et al., 1990; Kashiwagi et al., 1995), but other extracellular matrix macromolecules might also be involved. We did not measure uveoscleral outflow in the present study. However, the absence of differences between IOP and outflow facility, and thus in trabecular outflow, in eyes receiving active vs. heat-inactivated hyaluronidase or chondroitinase $\mathrm{ABC}$ allowed us to use differences in fluid flow from the external perfusion reservoir into the eye as a surrogate for differences in uveoscleral outflow, assuming no effects of the preparations on aqueous humor formation. We found no such differences. Since we did not study the ciliary muscle histochemically, we cannot know to what extent the substrates for our enzymes are present in the intermuscular connective tissue or, if present, how effectively the enzymes degraded them. Thus, our finding suggests only that intracameral administration of the enzymes does not alter the ciliary muscle's extracellular matrix in a manner relevant for uveoscleral outflow; whether the substrate GAGs themselves are relevant remains uncertain.

Our group (Gong et al., 1992; Gong and Freddo, 1994) has demonstrated that both sulfated and nonsulfated GAGs, including chondroitin sulfate and hyaluronic acid, actually decrease with age in the normal human eye, and hyaluronic acid is greatly decreased in the outflow pathway in eyes with POAG (Gong and Freddo, 1994; Knepper et al., 1996). However, aqueous outflow resistance increases with age in both humans (Gaasterland et al., 1978) and monkeys (Gabelt, Crawford and Kaufman, 1991), and in human glaucoma (Grant, 1951). This also suggests that the GAGs we have examined may not be as important in generating outflow resistance as previously thought.

\section{Acknowledgements}

Supported in part by the Glaucoma Research Foundation, San Francisco, CA, U.S.A.; Research to Prevent Blindness, New York, NY, U.S.A.; and by NIH grant EY02698. The biotinylated-hyaluronan binding protein was a gift from Charles Underhill, Ph.D.

\section{References}

Acott, T. S., Westcott, M., Passo, M. S. and Van Buskirk, E. M.(1985). Trabecularmeshwork glycosaminoglycans in human and cynomolgus monkey eyes. Invest. Ophthalmol. Vis. Sci. 26, 1320-9.

Bárány, E. H. (1953). In vitro studies of the resistance to flow through the angle of the anterior chamber. Acta Soc. Med. Upsal. 59, 260-76.

Bárány, E. H. (1964). Simultaneous measurement of changing intraocular pressure and outflow facility in the vervet monkey by constant pressure infusion. Invest. Ophthalmol. 3, 135-43.

Bárány, E. H. and Scotchbrook, S. (1954). Influence of testicular hyaluronidase on the resistance to flow through the angle of the anterior chamber. Acta Physiol. Scand. 30, 240-8.

Bernfield, M., Kokenyesi, R., Kato, M., Hinkes, M. T., Spring, J., Gallo, R. L. and Lose, E. J. (1992). Biology of the syndecans; A family of transmembrane heparan sulfate proteoglycans. Ann. Rev. Cell Biol. 8, 365-93.

Bill, A. (1975). Blood circulation and fluid dynamics in the eye. Physiol. Rev. 55, 383-417.

Crawford, K. and Kaufman, P. L. (1987). Pilocarpine antagonizes prostaglandin $\mathrm{F}_{2 \alpha}$-induced ocular hypotension in monkeys: evidence for enhancement of uveoscleral outflow by prostaglandin $\mathrm{F}_{2 \alpha}$. Arch. Ophthalmol. 105, 1112-16.

Erickson, K. A., Gonnering, R. S., Kaufman, P. L. and Dortzbach, R. K. (1984). The cynomolgus monkey as a model for orbital research: III. Effects on ocular physiology of lateral orbitotomy and isolation of the ciliary ganglion. Curr. Eye Res. 3, 557-64.

Gaasterland, D., Kupfer, C., Milton, R., Ross, K., McCain, L. and MacLellan, H. (1978). Studies of aqueous humor dynamics in man. VI. Effect of age upon parameters of intraocular pressure in normal human eyes. Exp. Eye Res. 26, 651-6.

Gabelt, B. T. and Kaufman, P. L. (1989). Prosaglandin $\mathrm{F}_{2 \alpha}$ increases uveoscleral outflow in the cynomolgus monkey. Exp. Eye Res. 49, 389-402.

Gabelt, B. T., Crawford, K. and Kaufman, P. L. (1991). Outflow facility and its response to pilocarpine decline in aging rhesus monkeys. Arch. Ophthalmol. 109, 879-82.

Gong, H., Freddo, T. F. and Johnson, M. (1992). Age-related changes of sulfated proteoglycans in the normal human trabecular meshwork. Exp. Eye Res. 55, 691-709.

Gong, H. and Freddo, T. F. (1994). Hyaluronic acid in the normal and glaucomatous human outflow pathway. Invest. Ophthalmol. Vis. Sci. 35 (ARVO suppl), 2083.

Grant, W. M. (1951). Clinical measurement of aqueous outflow. A.M.A. Archives of Ophthalmol. 46, 113-31.

Grant, W. M. (1963). Experimental aqueous perfusion in 
enucleated human eyes. Arch. Ophthalmol. 69, 783801.

Green, S. U., Tarone, G. and Underhill, C. B. (1988). Distribution of haluronate and hyaluronate receptors in the adult lung. J. Cell Sci. 89, 145-56.

Johnson, D. H., Bradley, J. M. B. and Acott, T. S. (1990). The effect of dexamethasone on glycosaminoglycans on human trabecular meshwork in perfusion organ culture. Invest. Ophthalmol. Vis. Sci. 31, 2568-71.

Kashiwagi, K., Lindsey, J. D., Kashiwagi, F. and Weinreb, R. N. (1995). Extracellular matrix changes induced by prostaglandins in cultured human ciliary muscle cells. Invest. Ophthalmol. Vis. Sci. 36 (ARVO suppl), 729.

Kaufman, P. L. and Bárány, E. H. (1976). Loss of acute pilocarpine effect on outflow facility following surgical disinsertion and retrodisplacement of the ciliary muscle from the scleral spur in the cynomolgus monkey. Invest. Ophthalmol. 15, 793-807.

Kaufman, P. L. and Crawford, K. (1989). Aqueous humor dynamics: how $\mathrm{PGF}_{2 \alpha}$ lowers intraocular pressure. In The ocular effects of prostaglandins and other eicosanoids (Eds Bito, L. Z. and Stjernschantz, J.). Pp. 387-416. Alan R. Liss: New York, U.S.A.

Kaufman, P. L. and Davis, G. E. (1980). Minified Goldmann applanating prism for tonometry in monkeys and humans. Arch. Ophthalmol. 98, 542-6.

Kaufman, P. L. and Gabelt, B. T. (1995). Presbyopia, prostaglandins and primary open angle glaucoma. In Glaucoma Update $V$. proceedings of the symposium of the glaucoma society of the international congress of ophthalmology in Quebec City, June 1994 (Eds Krieglstein, G. K.). Pp. 224-41. Springer-Verlag: New York-Berlin.

Kaufman, P. L., True-Gabelt, B'A. and Erickson-Lamy, K. A. (1988). Time-dependence of perfusion outflow facility in the cynomolgus monkey. Curr. Eye Res. 7, 721-6.

Keiser, H. D. and Hatcher, V. B. (1979). The effect of contaminant proteases in testicular hyaluronidase preparations on the immunological properties of bovine nasal cartilage proteoglycan. Conn Tiss. Res. 6, 229-33.

Knepper, P. A. (1980). Glycosaminoglycans and aqueous outflow resistance. PhD Thesis, Northwestern University, University Microfilms International, Ann Arbor, MI, U.S.A.

Knepper, P. A., Farbman, A. I. and Telser, A. G. (1984). Exogenous hyaluronidases and degradation of hyaluronic acid in the rabbit eye. Invest. Ophthalmol. Vis. Sci. 25, 286-93.

Knepper, P. A., Goossens, W., Hvizd, M. and Palmberg, P. F. (1996). Glycosaminoglycans of the human trabecular meshwork in primary open-angle glaucoma. Invest. Ophthalmol. Vis. Sci. 37, 1360-7.
Knepper, P. A., Hvizd, M. G., Goossens, W., Higbee, R. G. Gum, G. G. and Palmberg, P. F. (1989). GAG profile of human TM in primary open-angle glaucoma. Invest. Ophthalmol. Vis. Sci. 30 (Suppl), 224.

Lindsey, J. D., Kashiwagi, K., Boyle, D., Kashiwagi, F., Firestein, G. S. and Weinreb, R. N. (1996). Prostaglandins increase proMMP-1 and proMMP-3 secretion by human ciliary smooth muscle cells. Curr. Eye Res. 15, 869-75.

Melton, C. E. and DeVille, W. B. (1960). Perfusion studies on eyes of four species. Am. J. Ophthalmol. 50, 302-8.

Menage, M. J., Croft, M. A., Gange, S. J. and Kaufman, P. L. (1995). $\epsilon$-Aminocaproic acid does not inhibit outflow resistance washout in monkeys. Invest. Ophthalmol. Vis. Sci. 36, 1745-9.

Nilsson, S., Samuelsson, M., Bill, A. and Stjernschantz, J. (1989). Increased uveoscleral outflow as a possible mechanism of ocular hypotension caused by prostaglandin $\mathrm{F}_{2 \alpha}$-1-isopropylester in the cynomolgus monkey. Exp. Eye Res. 48, 707-16.

Ohya, T. and Kaneko, Y. (1970). Novel hyaluronidase from Strep Streptomyces. Biochem. Biophys. Acta 198, 607-9.

Pedler, C. (1956). The relationship of hyaluronidase to aqueous outflow resistance. Trans. Ophthalmol. Soc. U.K. 76, 51-63.

Peterson, W. S. and Jocson, V. L. (1974). Hyaluronidase effects on aqueous outflow resistance. Am. J. Ophthalmol. $77,573-7$.

Richardson, T. M. and Hutchinson, B. T. (1983). On the pathogenesis of primary open-angle glaucoma. Acta XXIV International Congress of Ophthalmology. Pp 52886. Lippincott: Philadelphia, U.S.A.

Sawaguchi, S., Yue, B., Yeh, P. and Tso, M. (1992). Effects of intracameral injection of chondroitinase $\mathrm{ABC}$ in vivo. Arch. Ophthalmol. 110, 110-17.

Tamm, E., Lütjen-Drecoll, E. and Rohen, J. (1990). Agerelated changes of the ciliary muscle in comparison with changes induced by treatment with prostaglandin $\mathrm{F}_{2 \alpha}$. An ultrastructural study in rhesus and cynomolgus monkeys. Mech. Ageing Dev. 51, 101-20.

Tamm, E., Rittig, M. and Lütjen-Drecoll, E. (1990). Elektronenmikroskopische und immunhistochemische untersuchungen zur augendruksenkenden wirkung von prostaglandin $\mathrm{F}_{2 \alpha}$. Fortschr. Ophthalmol. 87, 623-9.

Tawara, A., Varner, H. H. and Hollyfield, J. G. (1989). Distribution and characterization of sulfated proteoglycans in the human trabecular tissue. Invest. Ophthalmol. Vis. Sci. 30, 2215-31.

Van Buskirk, M. S. and Brett, J. (1978). The canine eye: in vitro dissolution of the barriers to aqueous outflow. Invest. Ophthalmol. Vis. Sci. 17, 258-63. 